\title{
EDITORIAL
}

\section{Percutaneous valvular intervention}

Percutaneous valvular intervention is a novel approach in the treatment of valvular diseases. The common percutaneous valvular interventions are mitral balloon valvuloplasty (PTMC), percutaneous mitral valve repair, aortic valvuloplasty, percutaneous aortic valve replacement, percutaneous and transapical aortic valve replacement, pulmonary valvuloplasty, percutaneous pulmonary valve replacement, percutaneous tricuspid valvuloplasty, percutaneous tricuspid valve replacement. ${ }^{1}$

The era of percutaneous therapy for valvular heart disease began with balloon valvuloplasty for pulmonic stenosis in the early 1980s. Following the demonstration of the success of this procedure, larger and additional balloon techniques were developed to treat mitral and aortic stenosis as well ${ }^{2}$.

Percutaneous mitral valvuloplasty (PTMC) opened the window of interventional treatment of valvular heart disease when it was first performed in 1982 in patients with rheumatic mitral stenosis. It established the percutaneous treatment of valvular heart diseases ${ }^{3-7}$.

Balloon aortic valvuloplasty was first done in 1985. Major limitation of balloon aortic valvuloplasty is the early recurrence of symptoms in patients. So its use is limited as bridge before the surgical procedures or as palliative measures in high-risk patients ${ }^{8}$.

Percutaneous aortic valve replacement was first performed by Cribier in April 2002 using the Cribier-Edwards valve. It can be done via antegrade transseptal, retrograde and transapical approach. Percutaneous aortic valve replacement is indicated in those patients who require aortic valve replacement but surgery is denied due to very old age, co-morbid conditions and severely depressed LV function. We hope that in near future these compassionate indications will be broadened to include the other patients. At present the ongoing issues of percutaneous aortic valve replacement are stable and accurate placement, prevention of the obstruction of coronary ostia, prevention of perivalvular aortic regurgitation, minimizing insertion site trauma from the current devices (19 to 21F, 6 to $8 \mathrm{~mm}$ diameter), ideal material of the valve (bio-compatibility-Biological valve/polymer) and balloon or pressureexpandable stents ${ }^{9-10,11 " .}$

Percutaneous tricuspid valvuloplasty started in 1987 for patients with tight tricuspid stenosis with or without mild TR. Percutaneous replacement of tricuspid valve is being tried in animal models (Phase I trial) $^{12}$.

Pulmonary valve replacement was started in 2000. The major drawback in pulmonary valve replacement is limitation in bovine jugular venous valve. It rarely exceeds 18 to $22 \mathrm{~mm}$ in diameter. Two strategies being promising in pulmonary valve replacement. These are minimally invasive surgery to downsize the outflow tract with two external rings and then valve implanted by percutaneous approach .A self expanding stent frame anchored in the enlarged pulmonary trunk and a centre designed to house the smaller jugular valve $^{13}$.

This is an exciting time in an arena that promises to be a new paradigm in the treatment of patients with mitral regurgitation. The timeline and pathway by which these devices are safely and effectively integrated into the current treatment of patients with mitral regurgitation is as yet undefined. Nonsurgical treatments for mitral 
regurgitation have focused on three main approaches to percutaneous mitral repair: indirect annuloplasty via the coronary sinus, direct transatrial, ventricular, or pericardial annuloplasty and edge-to-edge leaflet repair ${ }^{12}$.

Every day, there is new progress in the evolving innovative development in the percutaneous approaches of the management of valvular diseases. With the innovations of percutaneous valve replacement new rays of hope are shed on the group of the patients who denied surgery for high risks. Standing at this point when we look back, we see PTMC has gained its foothold. In developing countries it renders unmeasurable services to innumerable patients.

We can foresee that percutaneous mitral valve repair will be a complementary to surgical mitral valve repair in the near future. This is the field where lessons from the past suggest that a close collaboration between interventionists and surgeons is of utmost importance.

Endeavor of percutaneous transapical aortic valve replacement teaches us that apparently competitive procedures have had the virtue of approximating the cardiological and surgical groups, as the collaboration of a surgeon in a typical cardiological field and of a cardiologist in a typical surgeon's field is judged essential by almost everybody involved.

\section{ABDULLAH A S MAJUMDER MD, FACC, FRCP}

Professor of Cardiology, National Institute of Cardiovascular Diseases Sher-e-Bangla Nagar, Dhaka, Bangladesh

\section{References}

1. Davidson MJ, White JK, Bairn DS: Percutaneous therapies for valvular heart disease. Cardiovasc Pathol 2006; 15:123-129
2. VahanianA, PalaciosIF: Percutaneous approaches to valvular disease. Circulation 2004; 109(13):I572-1579

3. Palacios IF, Sanchez PL, Harrell LC, et al: Which patients benefit from percutaneous mitral balloon valvuloplasty? Prevalvuloplasy and postvalvuloplasty variables that predict long-term outcome. Circulation 2002; 105:1465.

4. Iung B, Garbarz E, Michaud P, et al): Percutaneous mitral commissurotomy for restenosis after surgical commissurotomy; Late efficacy and implications for patient selection. JAm Coll Cardiol 2000; 35:1295.

5. Cribier A, Elchaninoff H, Koning R, et al: Percutaneous mechanical mitral commissurotomy with a newly designed metallic valvulotome; Immediate results of the initial experience in 153 patients. Circulation 1999; 99:793.

6. Iung B, Cormier B, Ducimen'ere P, et al: Functional results 5 years after successful percutaneous mitral commissurotomy in a series of 528 patients and analysis of predictive factors, J Am Coll Cardiol 1996; 27:407.

7. Otto CM: Surgical and percutaneous intervention for mitral stenosis. In: Otto CM, ed. Valvular Heart Disease, 2nd ed. Philadelphia: Saunders; 2004:272-276.

8. Agarwal A, Kiiii AS, Attanti S, et al: Results of repeat balloon valvuloplasty for treatment of aortic stenosis in patients aged 59 to 104 years. Am J Cardiol 2005; 95(1):4347.

9. Cribier A, EItchaninoff $\mathrm{H}$, Iron $\mathrm{C}$, et al: Treatment of calcific aortic stenosis with the percutaneous heart valve: Mid-term follow-up from the initial feasibility studies: 
The French experience. J Am Coll Cardiol 2006; 47(6): 1214-1223.

10. Descoutures F, Himbert D, Lepage L, lung $\mathrm{B}$, De'taint $\mathrm{D}$, Tchetche $\mathrm{D}$, Brochet E, Castier Y, Depoix J-P, Nataf P, Vahanian A. Contemporary surgical or percutaneous manageme nt of severe aortic stenosis in the elderly. Eur Heart J; doi: 10.1093/ eurheartj/ehnOSL Published online ahead of print March 6, 2008.

11. AntunesMJ. Percutaneous aortic valve implantation. The demise of classical aortic valve replacement? (Editorial) Eur Heart J; doi: 10.10937
eurheartj/ehnOS 1. Published online ahead of print March 6, 2008.

12. Ted Feldman, MD; Howard C. Herrmann, MD; Fred St. Goar, MD: Percutaneous Treatment of Valvular Heart Disease: Catheter-Based Aortic Valve Replacement and Mitral Valve Repair Therapies. AJGC. 2006;15:291-301

13. Bonhoeffer P, Boudjemline Y, Qureshi SA, et al. Percutaneous insertion of the pulmonary valve. $\mathbf{J}$ Am Coll Cardiol 2002; 39: 16641669. 